\title{
Population structure and conservation of a high-altitude specialist, the Andean cat Leopardus jacobita
}

\author{
E. Daniel Cossíos ${ }^{1, *}$, R. Susan Walker ${ }^{2}$, Mauro Lucherini ${ }^{3}$, Manuel Ruiz-García ${ }^{4}$, \\ Bernard Angers ${ }^{1}$
}

\author{
${ }^{1}$ Department of Genetics and Evolution, University of Geneva. 1211, Genève 4, Switzerland \\ ${ }^{2}$ Wildlife Conservation Society, Junín de los Andes, 8371 Neuquén, Argentina \\ ${ }^{3}$ GECM, Universidad Nacional del Sur-CONICET, 8000 Bahía Blanca, Argentina \\ ${ }^{4}$ Pontificia Universidad Javeriana, Cra 7A No 43-82, Bogotá DC, Colombia
}

\begin{abstract}
The Andean cat Leopardus jacobita is considered one of the rarest felids in the world, although it has a large latitudinal distribution. Due to its preference for upland habitats, it has been suggested that this cat could have naturally fragmented populations. Despite great concern regarding the conservation status of this species, very little is known about its population structure, which is crucial information for appropriate management plans. In this study, we investigated its genetic diversity, population structure and evolutionary history by analysing 459 base pairs of the mitochondrial DNA control region, 789 base pairs of the NADH-5, ATP-8 and 16S mitochondrial genes, and 11 nuclear microsatellites, with the aim of identifying conservation units. The analyses were made on 30 skins and 65 recently collected faecal samples from throughout the known range of the species. These analyses revealed a total of 56 individuals. Our results confirm that Andean cat populations harbour extremely low mitochondrial and nuclear genetic diversity. The population structure of this species suggests the existence of 2 evolutionarily significant units (ESUs), with a latitudinal separation between 26 and $35^{\circ} \mathrm{S}$. In addition, 2 genetically distinct groups within the northern ESU could be considered separate management units.
\end{abstract}

KEY WORDS: Leopardus jacobita - Conservation genetics - Evolutionarily significant units · ESUs · Genetic structure · Microsatellites · Mitochondrial DNA · Phylogeography · South America

\section{INTRODUCTION}

The Andean cat Leopardus jacobita (Cornalia) is a small wild cat distributed along the Andes, from $10^{\circ} \mathrm{S}$ in central Peru (Cossíos et al. 2007b) to $38^{\circ} \mathrm{S}$ in central Argentina (Sorli et al. 2006, Novaro et al. 2010). This range includes several ecoregions which differ in terms of vegetation and amount and timing of precipitation, although all are characterised by a dry climate (Olson et al. 2001, WWF 2006). In spite of this relatively wide distribution, the scarcity of field observations and of other signs of presence suggests a low population density (Villalba et al. 2004, Lucherini et al. 2008). Many threats have been reported for the Andean cat, including hunting, habitat loss, predation by domestic dogs and prey reduction by humans (Villalba et al. 2004, Cossíos et al. 2007b, Lucherini \& Merino 2008). For these reasons, the Andean cat is currently considered one of the rarest cats of the world and the most endangered felid of the Americas (Nowell et al. 1996, Villalba et al. 2004, Acosta et al. 2008).

In the past decade, there has been a considerable effort to enhance knowledge about this species, but nevertheless it was recently identified as one of the felid species in critical need of research to support 
conservation efforts (Brodie 2009). Although our understanding of its distribution (Lucherini \& Luengos 2003, Perovic et al. 2003, Cossíos et al. 2007b) and ecology (Walker et al. 2007, Napolitano et al. 2008) has increased, detailed information about its population structure is still lacking. Due to the preference of this species for upland areas, some authors have indicated that the Andean cat could have naturally fragmented populations (Scrocchi \& Halloy 1986, Villalba et al. 2004). In addition, this felid has not been recorded currently between 30 and $35^{\circ} \mathrm{S}$ (Sorli et al. 2006), suggesting that populations from central Argentina could be isolated.

Previous research using genetic methods has shown a moderate level of genetic variation in mitochondrial DNA (mtDNA) for the species as a whole (Johnson et al. 1998), but relatively low levels of genetic variation in mtDNA in a population from northern Chile (Napolitano et al. 2008). Here, using mitochondrial and nuclear DNA markers, we assessed the variability and the structure of Andean cat populations throughout their range to ascertain whether they are fragmented and to identify conservation units in this species. Such an analysis can improve management and conservation planning for this endangered felid that has a large latitudinal distribution.

\section{MATERIALS AND METHODS}

\section{Sample collection}

In total, 30 Andean cat skin samples and 1073 carnivore faecal samples were collected between 2001 and 2008 in 11 different locations in the Andes of Peru, Bolivia and Argentina, from $10^{\circ} 3^{\prime} \mathrm{S}$ to $38^{\circ} 14^{\prime} \mathrm{S}$ (Table 1), by many field teams, covering the whole known distributional range of the species. Faecal samples were collected opportunistically and kept in individual paper bags in dry and cool conditions until DNA extraction (Wasser et al. 1997). For skin samples, 0.5 to $1 \mathrm{~cm}^{2}$ was cut from the ear of stuffed animals owned by villagers $(\mathrm{n}=29)$ or from museum specimens $(n=1)$ using sterilised instruments and kept in individual paper bags (Cossíos et al. 2007a). According to the villagers, the age of the skins varied from 2 mo to $10 \mathrm{yr}$. After the identification of the samples at the species and individual levels (see below), samples from 56 Andean cat individuals were available for mitochondrial DNA analyses, as well as 51 individuals for nuclear DNA analyses.

\section{Laboratory procedures}

DNA from skin samples was extracted following the standard phenol-chloroform protocol (Sambrook et al. 1989). DNA from faecal samples was isolated using the QIAamp ${ }^{\circledR}$ DNA Stool Mini Kit (Qiagen) according to the manufacturer's instructions with some modifications (Cossíos et al. 2009) and identified to the species level using a PCR-restriction fragment length polymorphism method (Cossíos \& Angers 2006). To prevent and monitor the contamination of samples during the laboratory processes, pre-PCR and post-PCR activities were carried out in different laboratories, and negative controls were included in each batch of extraction and amplification (Kohn \& Wayne 1997, Taberlet et al. 1999).

Table 1. Leopardus jacobita. Localities and sample size of the Andean cat samples analysed in this study as well as the number of individuals inferred a posteriori according to the number of different multilocus genotypes

\begin{tabular}{|c|c|c|c|c|c|c|c|}
\hline \multirow{2}{*}{ Country } & \multirow{2}{*}{ Locality } & \multicolumn{2}{|c|}{ - Coordinates } & \multirow[b]{2}{*}{ Faeces } & \multirow[b]{2}{*}{ Skins } & \multirow{2}{*}{$\begin{array}{r}\text { Samples } \\
\text { Total }\end{array}$} & \multirow[b]{2}{*}{ Individuals } \\
\hline & & $\mathrm{S}$ & W & & & & \\
\hline \multirow[t]{5}{*}{ Peru } & 1-Cuzco & $13^{\circ} 44^{\prime}$ & $71^{\circ} 12^{\prime}$ & 2 & 0 & 2 & 2 \\
\hline & 2-Central Peru & $10^{\circ} 13^{\prime}-12^{\circ} 19^{\prime}$ & $75^{\circ} 41^{\prime}-76^{\circ} 57^{\prime}$ & 4 & 2 & 6 & 5 \\
\hline & 3-Ayacucho & $14^{\circ} 04^{\prime}$ & $73^{\circ} 51^{\prime}$ & 0 & 1 & 1 & 1 \\
\hline & 4-Arequipa & $14^{\circ} 59^{\prime}-15^{\circ} 56^{\prime}$ & $71^{\circ} 14^{\prime}-72^{\circ} 42^{\prime}$ & 1 & 2 & 3 & 3 \\
\hline & 5-Tacna/Puno & $16^{\circ} 29^{\prime}-17^{\circ} 19^{\prime}$ & $69^{\circ} 29^{\prime}-70^{\circ} 27^{\prime}$ & 2 & 9 & 11 & 10 \\
\hline \multirow[t]{2}{*}{ Bolivia } & 6-La Paz/Oruro & $17^{\circ} 08^{\prime}-18^{\circ} 26^{\prime}$ & $68^{\circ} 07^{\prime}-69^{\circ} 22^{\prime}$ & 2 & 9 & 11 & 10 \\
\hline & 7-Potosi & $20^{\circ} 05^{\prime}-22^{\circ} 09^{\prime}$ & $67^{\circ} 14^{\prime}-67^{\circ} 53^{\prime}$ & 14 & 3 & 17 & 7 \\
\hline \multirow[t]{4}{*}{ Argentina } & 8-Jujuy & $21^{\circ} 57^{\prime}-23^{\circ} 04^{\prime}$ & $66^{\circ} 03^{\prime}-66^{\circ} 18^{\prime}$ & 30 & 0 & 30 & 7 \\
\hline & 9-Catamarca & $25^{\circ} 13^{\prime}-26^{\circ} 39^{\prime}$ & $66^{\circ} 43^{\prime}-67^{\circ} 39^{\prime}$ & 7 & 0 & 7 & 4 \\
\hline & 10-Tucuman & $26^{\circ} 30^{\prime}$ & $65^{\circ} 48^{\prime}$ & 1 & 0 & 1 & 1 \\
\hline & $\begin{array}{l}\text { 11-Mendoza/ } \\
\text { Neuquén }\end{array}$ & $35^{\circ} 59^{\prime}-38^{\circ} 14^{\prime}$ & $65^{\circ} 48^{\prime}-69^{\circ} 49^{\prime}$ & 2 & 4 & 6 & 6 \\
\hline Total & & & & 65 & 30 & 95 & 56 \\
\hline
\end{tabular}


Two segments of the hypervariable domain 1 (HVS-I) of the mitochondrial control region were amplified with the primer pairs CH3F-H1rev and H2for-CH3R (Freeman et al. 2001, Cossíos et al. 2009). The mitochondrial genes NADH-5, ATP-8 and $16 \mathrm{~S}$ were amplified with the primer pairs ND5.1F$\mathrm{ND} 5 \cdot 2 \mathrm{R}, \mathrm{AP} 8 \cdot 1 \mathrm{~F}-\mathrm{AP} 8 \cdot 2 \mathrm{R}$ and $16 \mathrm{~S} \cdot 1 \mathrm{~F}-16 \mathrm{~S} \cdot 4 \mathrm{R}$, respectively (Johnson et al. 1998). Amplification reactions were carried out in a volume of $30 \mu \mathrm{l}$ containing a final concentration of $20 \mathrm{mM}$ Tris- $\mathrm{HCl}(\mathrm{pH} 8.4)$, $50 \mathrm{mM} \mathrm{KCl}, 1.5 \mathrm{mM} \mathrm{MgCl}_{2}, 0.1 \mathrm{mM}$ of each dNTP, $0.8 \mathrm{pM}$ of each primer, $0.8 \mathrm{mg} \mathrm{ml}^{-1}$ of BSA, 0.2 units of Taq DNA polymerase and approximately $40 \mathrm{ng}$ of template DNA. PCR conditions included an initial denaturing step at $92^{\circ} \mathrm{C}$ for $2 \mathrm{~min}, 45$ cycles of $92^{\circ} \mathrm{C}$ for $30 \mathrm{~s}, 52^{\circ} \mathrm{C}$ for $30 \mathrm{~s}$ and $68^{\circ} \mathrm{C}$ for $40 \mathrm{~s}$, and a final extension step at $68^{\circ} \mathrm{C}$ for $5 \mathrm{~min}$. The products were sequenced with a CEQ 8000XL DNA Analysis System (Beckman Coulter). HVS-1, NADH-5, 16S and ATP-8 sequences have been deposited in GenBank (accession numbers FJ960826 to 36).

We used 11 microsatellite loci characterised in domestic cats and located on different chromosomes (Fca8, Fca24, Fca31, Fca43, Fca45, Fca80, Fca90, Fca96, Fca173, Fca176 and Fca294; MenottiRaymond et al. 1999). PCR conditions were the same as those for mtDNA but with an annealing temperature of $55^{\circ} \mathrm{C}$.

\section{Identification of individuals}

A comparative multitube PCR approach was followed to create consensus microsatellite genotypes (Taberlet et al. 1996, Frantz et al. 2003). Genotypes were determined through 2 positive PCR reactions for heterozygotes and 3 for homozygotes (Frantz et al. 2003). Genotyping error rates due to allelic dropout and false alleles (FA) were calculated following Broquet \& Petit (2004). The probability of identity $\left(\mathrm{P}_{\mathrm{ID}}\right.$, i.e. the probability that 2 individuals drawn at random will have the same genotype at multiple loci) was calculated to evaluate the power of our marker set for individual identification. Given a low $\mathrm{P}_{\mathrm{ID}}$, samples with the same multilocus genotype were assigned to a single individual.

For the mtDNA analyses, additional individuals were identified, even in absence of satisfactory microsatellite amplification, if they met 1 of the following conditions: (1) they were the only Andean cat faecal samples from a particular locality; (2) they differed with respect to mtDNA sequences from the other faecal samples from the same locality.

\section{Microsatellite data analysis}

We estimated expected heterozygosity $\left(H_{\mathrm{e}}\right)$ and number of alleles $(k)$ using the computer program ARLEQUIN 2.00 (Schneider et al. 2000). Allelic richness $\left(A_{\mathrm{r}}\right)$ and fixation index $\left(F_{\text {is }}\right)$ were estimated with FSTAT 2.9.3 (Goudet 1995). We tested for $F_{\text {is }}$ significance using 10000 permutations of the data. The program CONVERT (Glaubitz 2004) was used to identify private microsatellite alleles, which are alleles present in one population and not shared with any other.

To infer population organisation, a Bayesian clustering method was performed using STRUCTURE 2.3 (Pritchard et al. 2000), with a precautionary 100000 burn-in period and 1000000 Markov chain Monte Carlo repetitions, to infer the number of populations $(K)$ and to assign individuals to inferred population clusters. This method assigns to individuals a membership coefficient for each population, based on allele frequencies. We performed 10 independent runs for each value of $K$, from 1 to 6 , using the admixture model. The number of populations best fitting our data set was defined both using the mean value of the log probabilities $[\operatorname{Pr}(\mathrm{X} / K)]$ for each $K$ value, and the most positive $\Delta K$ (Evanno et al. 2005). Additionally, we used GENETIX 4.05.2 (Belkhir et al. 1996) to perform a factorial correspondence analysis (FCA). STRUCTURE 2.3 was used to evaluate the fidelity of each of the genotypes to their population sample by completing the maximum likelihood assignments with the known population data (option Popinfo activated). We considered that individuals were correctly assigned to a population when their q-value (i.e. their posterior probability of belonging to an original population) was at least $90 \%$ (Pritchard et al. 2000). We then carried out a hierarchical analysis of molecular variance (AMOVA; Excoffier et al. 1992) with the groups inferred by the analysis with STRUCTURE, using $\Phi$-statistics calculated with ARLEQUIN 2.00 and 10000 permutations to assess statistical significance. We also tested microsatellite data from these groups for Hardy-Weinberg (HW) equilibrium with the method developed by Guo \& Thompson (1992) using GENEPOP 3.4 (Raymond \& Rousset 1995).

\section{Mitochondrial data analysis}

We used ARLEQUIN 3.5 (Excoffier \& Lischer $2010)$ to estimate nucleotide diversity $\left(\pi_{i}\right.$ Tajima 1983) and haplotype diversity (hd; Nei 1987) for the 
mitochondrial data. A minimum spanning network (Templeton et al. 1992) was constructed with the mitochondrial sequences, using the program TCS 1.21 (Clement et al. 2000), with the confidence of connection limits set at $95 \%$ and considering gaps as a fifth mutational state. The network was rooted in order to identify the current Andean cat lineages and to evaluate their monophyly using pampas cat Leopardus colocolo (Molina) haplotypes from Cossíos et al. (2009) and Napolitano et al. (2008) as an outgroup. The pampas cat was chosen because it is the presumptive sister species of the Andean cat (Johnson et al. 2006), so fewer homoplasies are expected than with other felid species. The root probability method implemented in TCS ignores inferred haplotypes to root networks (Cassens et al. 2003), and therefore was not used here. Neighbour-joining (NJ) and maximum-likelihood (ML) methods were performed on the entire 1248 bp sequences using PAUP 4.01b (Swofford 1993) to confirm relationships among haplotypes and infer the position of the root, using 1000 bootstrap replicates and a domestic cat (NCBI reference sequence: NC 001700.1) and a pampas cat (C5; Cossíos et al. 2009) as outgroups. After choosing a model using MODELTEST 3.7 (Posada \& Crandall 1998), the Tamura-Nei model (Tamura \& Nei 1993) was used for constructing NJ and ML trees, assuming a gamma distribution with a 0.3 shape parameter for substitution rates across sites.

To estimate time since the most recent ancestor of current Andean cat haplotypes, we performed 3 analyses using the estimator $T=D / 2 \mu l$ (Tang et al. 2002), where $D$ is the number of pairwise nucleotide differences, $\mu$ is the mutation rate per site, and $l$ is the length of the sequenced region. The number of differences between sequences was calculated with ARLEQUIN 3.5 and the TamuraNei model of substitution. For the first analysis, a mutation rate of $0.67 \%$ per million years (MY) was assumed for the combined NADH-5, ATP-8 and 16S mitochondrial genes, as estimated for the family Felidae by Johnson et al. (1999). The second analysis considered a mutation rate of $3.21 \% \mathrm{MY}^{-1}$ (range: 2.195 to $4.62 \%$ ) for 341 bp of the HVS-I, based on sequences from the closely related pampas cat presented by Cossíos et al. (2009). For the third analysis, we estimated the mutation rate of $390 \mathrm{bp}$ of the HVS-I region based on a divergence time of 2.91 (2.02 to 4.25) MY between Andean cat and the clade formed by the margay Leopardus wiedii (Schinz) and the ocelot L. pardalis (Linnaeus) (Johnson et al. 2006).

\section{RESULTS}

\section{Identification of species and individuals}

Of 1073 faecal samples, 65 were identified as Andean cat $(6 \%)$, while 820 were pampas cat $(76.4 \%)$. Three of the samples were Geoffroy's cats Leopardus geoffroyi (D'Orbigny \& Gervais), 19 were domestic cats, 71 were canid species, and 95 failed to be amplified and could not be identified. The 30 skin samples were all from Andean cats, making a total of 95 Andean cat samples.

One of the 11 microsatellite loci failed to provide consistent amplifications (Fca45), and 3 were monomorphic (Fca43, Fca80 and Fca90). We used the 7 remaining loci for identification of individuals and further analyses. These markers were successfully amplified for the 30 skin samples $(100 \%)$, but they gave consistent results for only $46(70.8 \%)$ of the 65 Andean cat faecal samples, reducing the number of samples suitable for further microsatellite analyses to 76. Allelic dropout rates ranged from 15.2 to $22 \%$ per locus, with a weighted average over all 7 loci of 18.1. FAs occurred in 11 of 1596 PCR reactions (FA = $0.69 \%)$. These overall genotyping error rates were comparable to other non-invasive genetic studies (Broquet \& Petit 2004) and are acceptable for individual identification.

For the 76 samples suitable for microsatellite analyses, 51 unique multilocus genotypes were identified and assigned to the same number of individuals. No more than 4 samples were assigned to the same individual. The probability of sampling 2 different individuals with the same genotype $\left(\mathrm{P}_{\mathrm{ID}}\right)$ ranged between $1.45 \times 10^{-10}$ and $1.81 \times 10^{-3}$ depending on the locality, suggesting that samples with the same genotype represented the same individual. Five additional individuals were identified based on their mtDNA sequences only, so mtDNA analyses were performed on 56 individuals.

\section{Mitochondrial DNA diversity}

Sequences of $459 \mathrm{bp}$ were obtained for the mitochondrial HVS-I, and segments of 318, 189 and 282 bp were determined for the NADH-5, ATP-8 and 16S genes, respectively, for a total of $1248 \mathrm{bp}$. Sequencing revealed a total of 5 haplotypes, named hereafter LjaA to LjaE. HVS-I was the most variable locus surveyed, with 10 variable sites, followed by NADH-5 with 3 and, finally, 16S and ATP-8 with a single variable site each (Table 2). Considering only the 
Table 2. Leopardus jacobita. Reduced CLUSTAL W (Thompson et al. 1994) alignment of part of the Andean cat HVS-I, 16S, ATP-8 and NADH-5 mitochondrial sequences, showing only variable sites. Oja1, 2, 3, 4, 83 and 84 from Johnson et al. (1998). For the pampas cat (Napolitano et al. 2008, Cossíos et al. 2009), only sites equivalent to variable sites in the Andean cat are shown. Underscores (_) and question marks (?) represent deletions and missing data, respectively. Position refers to the complete domestic cat mtDNA sequence (Lopez et al. 1996)

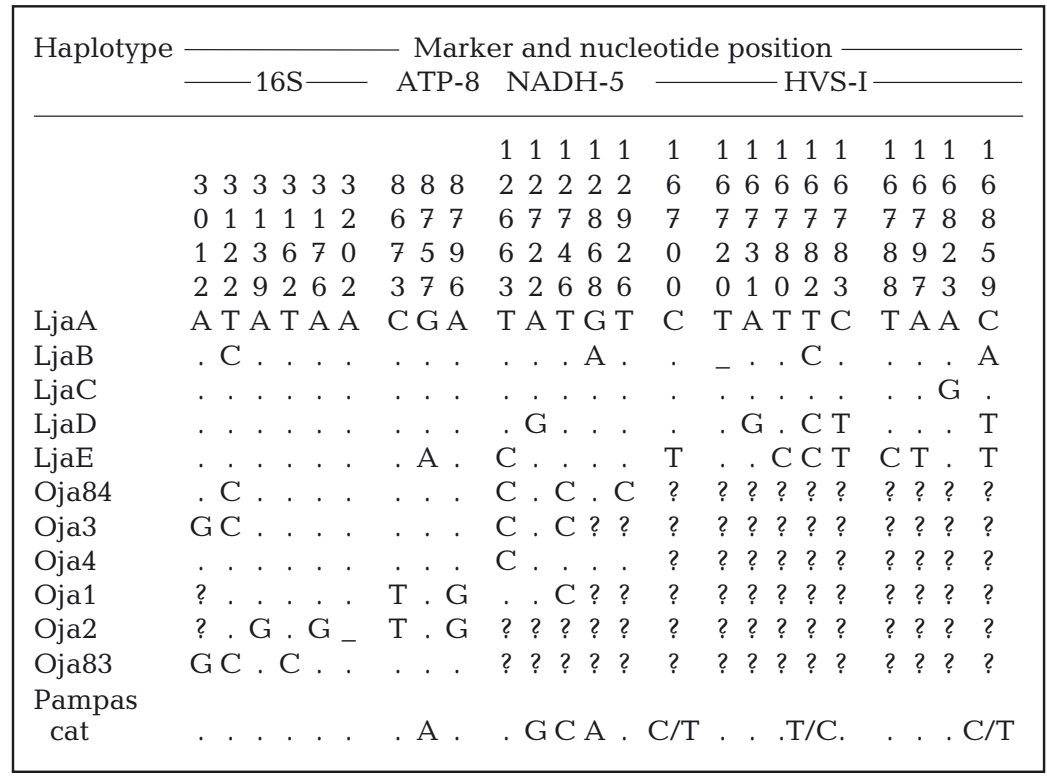

The total number of alleles per population ranged from 17 to 48, but was correlated with the sampling size $\left(\mathrm{r}^{2}=\right.$ 0.8375). The allelic richness calculated for 5 inds. population ${ }^{-1}$ with FSTAT 2.9.3 (Goudet 1995) ranged from 17.16 to 24.85, showing no important differences between populations. The gene diversity ranged from 0.58 and 0.78 (Table 4) and was clearly not correlated with the sampling size $\left(r^{2}=0.0002\right)$.

\section{Evolutionary history}

The minimum spanning network highlights the divergence among haplotypes (Fig. 1). Excluding haplotypes A to $C$, separated by a single mutation, all other pairwise comparisons are separated by 5 to 12 mutations, with a mean of 7.0 mutations. The limit of mutational connections between pairs of sequences justified by the parsimony criterion was 15, as calculated by TCS

5 Andean cat haplotypes detected during this survey, 3 of the 15 variable sites were informative, whereas when the 6 haplotypes found by Johnson et al. (1998) were added, 9 of 24 variable sites were informative. The number of haplotypes per locality ranged from 1 to 3 . Only 1 haplotype was detected in 6 of the 11 localities $(2 ; 3 ; 8 ; 9 ; 10 ; 11$; Table 3$)$. For the variable localities, haplotype diversity values ranged from 0.28 to 0.67 , and nucleotide diversity varied between 0.0011 and 0.0027 (Table 3).

The haplotypes Lja1 and Lja2 reported by Napolitano et al. (2008) for the NADH-5, ATP8 and 16S genes were identical to the corresponding segments of the haplotypes LjaA and LjaD, respectively. The haplotypes reported by Johnson et al. (1998) for the same genes were not detected in this research.

\section{Microsatellite diversity}

Loci Fca08, Fca31 and Fca294 failed to be amplified for only 1 of the 51 Andean cat individuals, while loci Fca24 and Fca176 failed to be amplified for 2 and 3 individuals, respectively. The total number of microsatellite alleles per locality and locus ranged from 1 to 5 (Table 4). The size of each microsatellite is shown in Table 5.
1.21 (Clement et al. 2000). The most recent ancestor of the Andean cat is not clearly defined in the network, as 3 haplotypes were equally parsimonious, with 1 fewer mutation than LjaA between these undetected haplotypes and the pampas cat. The haplotypes described by Johnson et al. (1998) lack the sequences of 1 or more markers used here (Table 2), and it was not possible to determine their position in the network, as well as in the NJ and ML trees.

NJ and ML methods provided consistent results, clustering haplotypes A, B and C, as well as showing strong bootstrap values for the association between $\mathrm{A}$ and $C$ (942/1000), and for the totality of the Andean cat haplotypes (1000/1000). Relationships among the A-B-C cluster and haplotypes D and E were not resolved, and the position of the root was not defined (not shown), which is consistent with the minimal spanning network. The topology of the trees did not change when only pampas cats or domestic cats were used as outgroups.

The 3 analyses used to estimate time since the most recent ancestor $(T)$ of the current Andean cat haplotypes provided similar results. For the combined NADH-5, ATP-8 and 16S mitochondrial genes, a mean Tamura-Nei distance of 2.3 was found among Andean cat haplotypes. Considering a mutation rate per site of $0.0067 \mathrm{MY}^{-1}$ and a sequence length of 


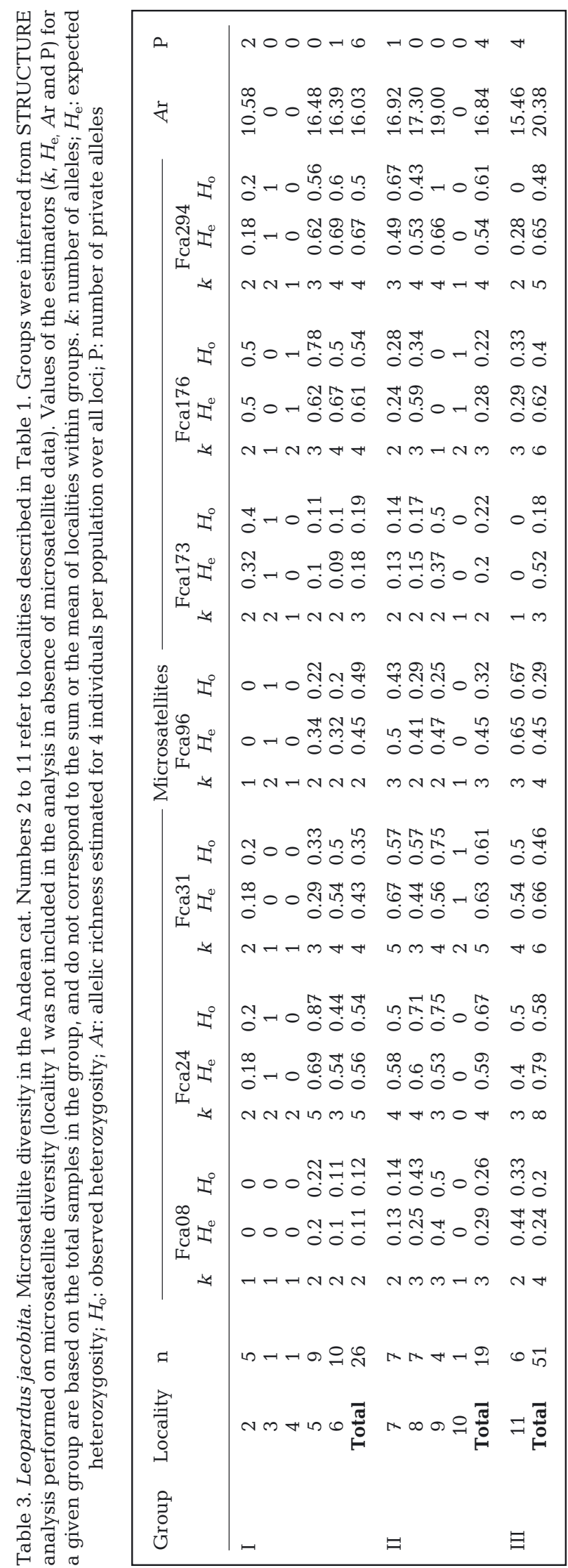

$789 \mathrm{bp}, T$ was estimated as 217543 yr. For the HVS-I region, a mean Tamura-Nei distance of 5.97 was found between haplotypes A-B-C and D-E, situated at opposite sides of the inferred parsimony network (Fig. 1). When using the $341 \mathrm{bp}$ homologous portion of the pampas cat HVS-I and considering a mutation rate per site of $0.321 \mathrm{MY}^{-1}$ (range: 0.02195 to 0.0462 ), the common ancestor of the current Andean cat haplotypes was dated at 272700 (189473 to 398800$)$ yr. For the third analysis, an average of 60.11 differences was found for the HVS-I region between Andean cat and the ocelot-margay clade. Assuming a divergence time of 2.91 (2.02 to 4.25) MY between them, the mutation rate was calculated as 0.0265 (0.018 to 0.038) mutations site $^{-1} \mathrm{MY}^{-1}$. Using these data and considering 5.97 differences between the 2 Andean cat haplotype groups, the most recent common ancestor of the current Andean cat haplotypes was dated at 288824 (201417 to 425214 ) yr.

\section{Population structure}

Using the program STRUCTURE, we obtained the most positive values of both $\Delta K(10.07)$ and $\ln \operatorname{Pr}(\mathrm{XI} K)$ (-507.1), for $K=3$, indicating that a clustering of the individuals in 3 groups best fits the data (Fig. 2A).

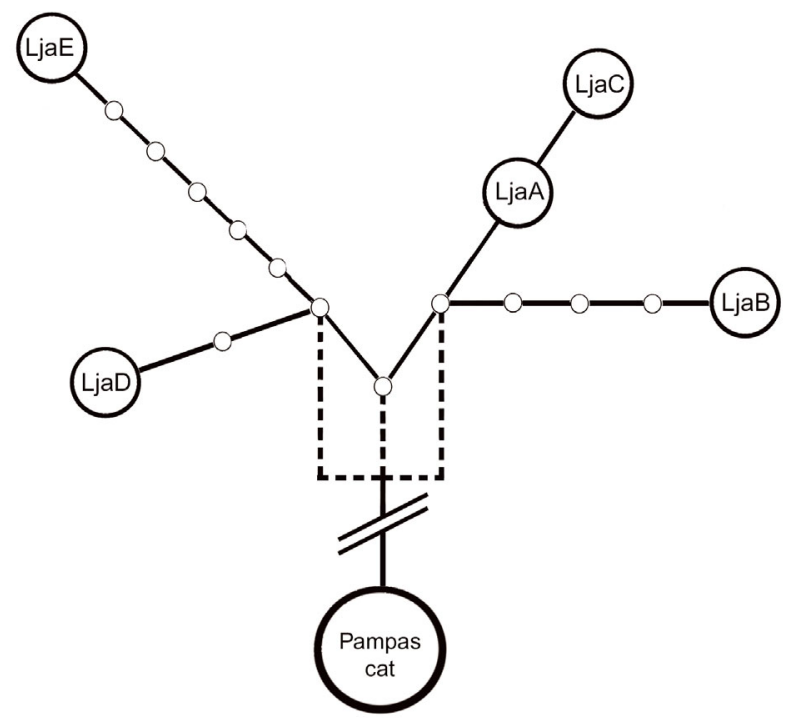

Fig. 1. Leopardus jacobita. Minimum spanning network for Andean cat HVS-I, NADH-5, ATP-8 and 16S combined sequences. Sizes of the circles are not proportional to the haplotype frequency. Each solid line represents 1 mutational step, and small open circles indicate undetected intermediate haplotype states. Dashed lines represent possible relationships between haplotypes, when more than 1 possibility exists 
These 3 groups of populations are strongly structured geographically and corresponded to localities 2 to 6 (population group I), 7 to 10 (group II) and 11 (group III; Fig. 2B). The FCA plot of individual microsatellite genotypes made with GENETIX supported the same 3 groups (Fig. 2C). When performing the population assignment test considering these 3 population groups, 50 of 51 individuals showed a q-value $>0.9$ and were assigned to their original populations. The remaining individual, with a $\mathrm{q}=0.86$, was considered probably admixed (Fig. 2B). The results of hierarchical AMOVA with microsatellite data confirmed the relevance of this structure, as an important proportion of the total variation was detected among groups $(51.66 \%, \mathrm{p}=0.017)$, and only $1.59 \%$ $(\mathrm{p}=0.086)$ was accounted for by differences among populations within groups. Population groups I, II and III have 6, 4 and 4 microsatellite private alleles, respectively (Table 3 ). Deviation from HW expectations and inbreeding were not detected for any microsatellite and population group (Table 4).

A strong geographic congruence was observed between microsatellites and mitochondrial genomes (Fig. 3). Haplotype A was widely distributed and was detected at nearly all sites. Haplotypes B and D were restricted to group I (localities 2 to 6 ), while haplotype E, separated by 8 mutations from the nearest haplotype (D), was characteristic of site 11 (group III). Haplotype $\mathrm{C}$ was found in a single individual at site 1. Group I was the most genetically diverse, especially localities 5 and 6 with 3 different haplotypes. Fu's test was significantly positive only for locality 5 , as well as for group I (Table 5).

\section{DISCUSSION}

\section{Genetic diversity}

The extremely low genetic diversity of the Andean cat is striking. Only 5 mitochondrial haplotypes were detected for the entire species, with no more than 3 within a population, although the low sample size could have contributed to an underestimation of within-pop-

Table 5. Leopardus jacobita. Mitochondrial DNA diversity in the Andean cat, for the combined HVS-I, NADH-5, ATP8 and 16S sequences. Numbers 1 to 11 refer to localities described in Table 1. Locality 1 was not included in the structure analysis in absence of microsatellite data. n: sample size; $H$ : number of haplotypes; hd: haplotype diversity; $S$ : number of polymorphic sites; $P$ : proportion of variable sites; $\pi$ : nucleotide diversity; np: cannot be computed; *: significant at $\mathrm{p}<0.05$

\begin{tabular}{|c|c|c|c|c|c|c|c|c|c|c|c|c|c|}
\hline \multirow{2}{*}{ Group } & \multirow{2}{*}{ Locality } & \multicolumn{5}{|c|}{ - Haplotypes } & \multirow[t]{2}{*}{$\mathrm{n}$} & \multirow[t]{2}{*}{$H$} & \multirow{2}{*}{$\mathrm{hd} \pm \mathrm{SD}$} & \multirow[t]{2}{*}{$S$} & \multirow[t]{2}{*}{$P$} & \multirow[t]{2}{*}{$\pi \pm \mathrm{SD}$} & \multirow{2}{*}{$\begin{array}{c}\text { Fu's } \\
\text { Fs }\end{array}$} \\
\hline & & A & $\mathrm{B}$ & $\mathrm{C}$ & $\mathrm{D}$ & $\mathrm{E}$ & & & & & & & \\
\hline \multirow[t]{7}{*}{ I } & 1 & 1 & 0 & 1 & 0 & 0 & 2 & 2 & $1 \pm 0.5$ & 1 & 0.08 & $0.0008 \pm 0.001$ & 0 \\
\hline & 2 & 0 & 5 & 0 & 0 & 0 & 5 & 1 & 0 & 0 & 0 & 0 & np \\
\hline & 3 & 1 & 0 & 0 & 0 & 0 & 1 & 1 & 0 & 0 & 0 & 0 & $\mathrm{np}$ \\
\hline & 4 & 2 & 1 & 0 & 0 & 0 & 3 & 2 & $0.67 \pm 0.314$ & 5 & 0.4 & $0.0027 \pm 0.002$ & 2.35 \\
\hline & 5 & 5 & 4 & 0 & 1 & 0 & 10 & 3 & $0.64 \pm 0.101$ & 8 & 0.64 & $0.0027 \pm 0.002$ & $3.49^{*}$ \\
\hline & 6 & 6 & 3 & 0 & 1 & 0 & 10 & 3 & $0.60 \pm 0.13$ & 8 & 0.64 & $0.0025 \pm 0.002$ & 3.23 \\
\hline & Total & 14 & 13 & 0 & 2 & 0 & 29 & 3 & $0.58 \pm 0.045$ & 8 & 0.64 & $0.0024 \pm 0.001$ & $5.92^{*}$ \\
\hline \multirow[t]{5}{*}{ II } & 7 & 6 & 1 & 0 & 0 & 0 & 7 & 2 & $0.28 \pm 0.196$ & 5 & 0.4 & $0.0011 \pm 0.001$ & 2.50 \\
\hline & 8 & 7 & 0 & 0 & 0 & 0 & 7 & 1 & 0 & 0 & 0 & 0 & $\mathrm{np}$ \\
\hline & 9 & 4 & 0 & 0 & 0 & 0 & 4 & 1 & 0 & 0 & 0 & 0 & $\mathrm{np}$ \\
\hline & 10 & 1 & 0 & 0 & 0 & 0 & 1 & 1 & 0 & 0 & 0 & 0 & np \\
\hline & Total & 18 & 1 & 0 & 0 & 0 & 19 & 2 & $0.10 \pm 0.092$ & 5 & 0.4 & $0.0004 \pm 0.0004$ & 1.71 \\
\hline \multirow[t]{2}{*}{ III } & 11 & 0 & 0 & 0 & 0 & 6 & 6 & 1 & 0 & 0 & 0 & 0 & $\mathrm{np}$ \\
\hline & Total & 33 & 14 & 1 & 2 & 6 & 56 & 5 & $0.60 \pm 0.056$ & 15 & 1.2 & $0.0031 \pm 0.001$ & \\
\hline
\end{tabular}




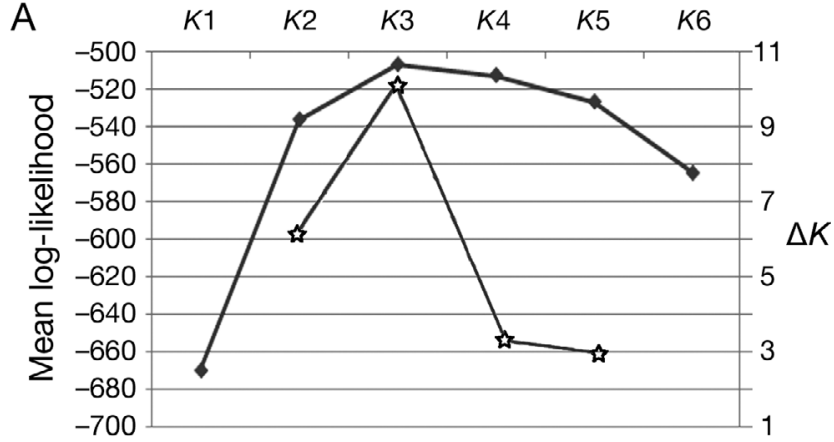

B

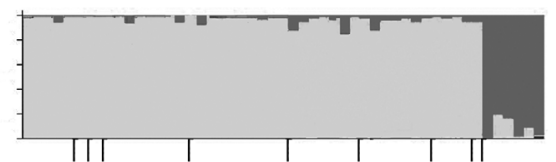

$K=2$

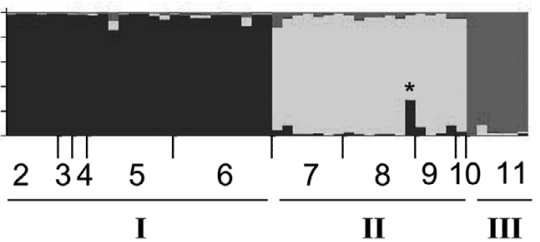

$K=3$

Localities

Groups

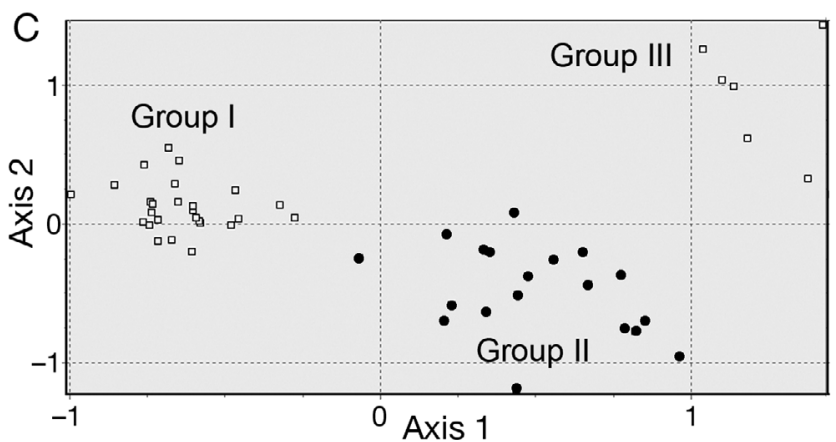

Fig. 2. Leopardus jacobita. Population structure inferred from microsatellite data. (A) Mean log-likelihood, across 10 independent runs, computed with the program STRUCTURE for each value of $K$ (= number of populations) ranging from 1 to 6 ( $)$ and value of $\Delta K(\xi)$; the highest value of $\Delta K$ points to the most likely number of partitions (Evanno et al. 2005). (B) Membership coefficients inferred for $K=2$ and $K=3$. Each individual is represented by a column, and each of the inferred population groups is represented by a black/grey shade. Localities correspond to those in Table 1 and are arranged from north (left) to south. *: a putative admixed individual. (C) Factorial correspondence analysis (FCA) plot showing the 3 groups previously identified with STRUCTURE

ulation haplotype diversity. Nevertheless, the present survey covers the great majority of the known range of the Andean cat (Marino et al. 2011), suggesting that the low number of haplotypes with a large geographic distribution is probably representative of the current mtDNA diversity of the species. Such a low level of diversity is comparable to that

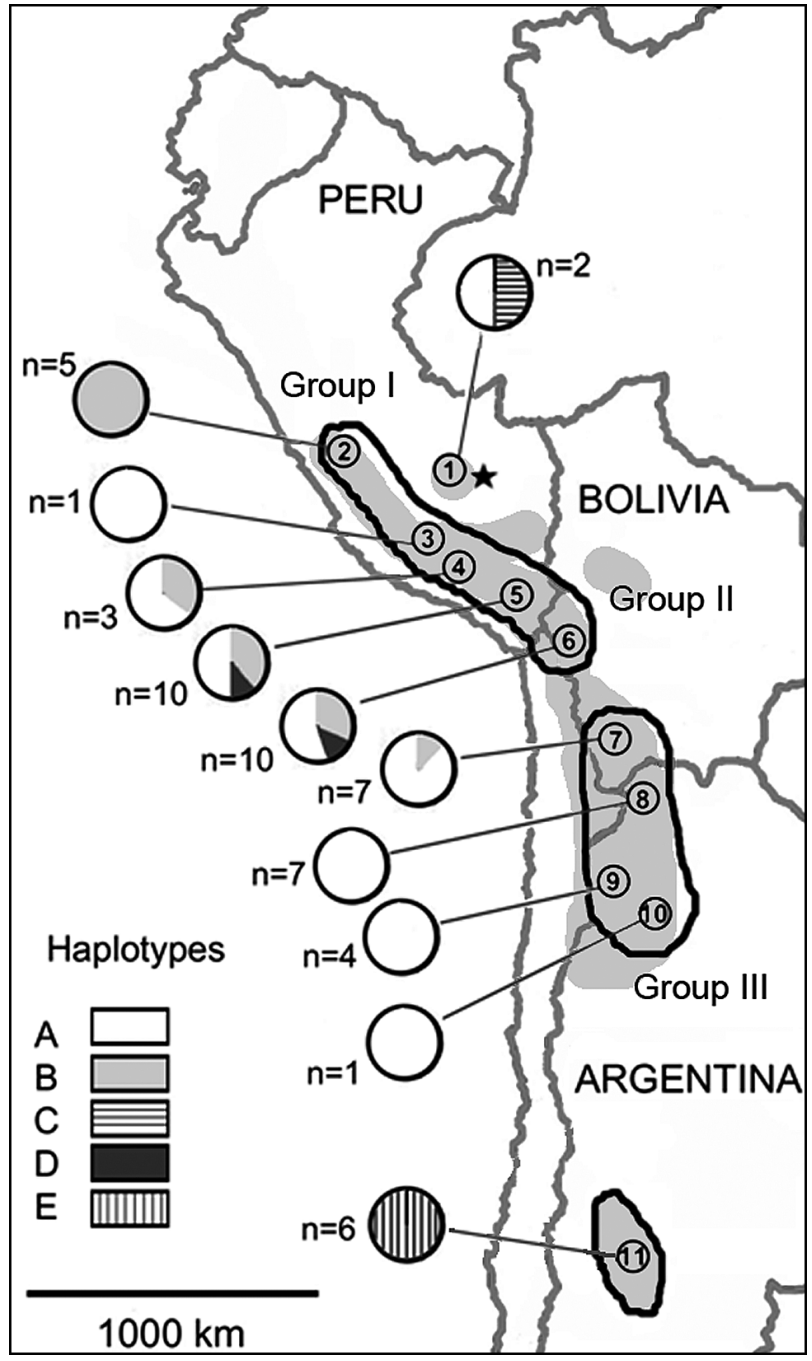

Fig. 3. Leopardus jacobita. Geographic structure of Andean cat populations. Proportion of the mtDNA haplotypes is shown for each sampled locality. Locality numbers are encircled and correspond to those in Table 1. Populations assigned to a given group according to STRUCTURE 2.2 (Pritchard et al. 2000) analysis are encircled. Locality 1, represented by a star, was not included in the structure analysis due to absence of microsatellite data. Gray areas refer to the approximate distribution of the Andean cat, following Acosta et al. (2008)

observed in other endangered species, such as the Iberian lynx Lynx pardinus (Temminck) (1 to 2 haplotypes per population, Johnson et al. 2004), the cheetah Acinonyx jubatus (Schreber) (1 to 6, considering HVS-I only, Freeman et al. 2001), the Ethiopian wolf Canis simensis (Rüppell) (1 to 4, HVS-I only, Gottelli et al. 2004) and the spectacled bear Tremarctos ornatus (FG Cuvier) (1 to 3, HVS-I only, Ruiz-García 2007). The reduced mitochondrial diversity at the population level, the separation of the current haplo- 
types by several mutational steps and the results of Fu's test could be indicative of bottlenecks. The absence in our survey of the haplotypes found by Johnson et al. (1998) was surprising. This difference could be the result of non-sampled isolated localities, recent haplotype extinctions and/or errors in the sequencing of degraded DNA. Because the research of Johnson et al. (1998) was based on samples from museum specimens, errors in their sequences are a plausible explanation. For instance, the Andean cat haplotype Oja2 is identical to the ocelot Lpa11 (both from Johnson et al. 1998) for the 16S locus, suggesting misidentification or contamination of the sample.

The microsatellite diversity of the Andean cat is also very low compared to other members of the genus Leopardus. Allelic richness estimated for 4 loci (Fca24, 31, 96 and 294) and 6 ind. population ${ }^{-1}$ was always far lower in the Andean cat $(A r=11.00-12.58$, this study) than in the pampas cat $(\mathrm{Ar}=16.25-22.91$; Cossíos et al. 2009) living in the same localities. Similarly, the number of alleles for the loci Fca08 and Fca96 is 3 to 5 times larger in ocelots, margays and little spotted cats L. tigrinus (Schreber) from Brazil (Grisolia et al. 2007) than in the Andean cat. In addition, a large portion of the genetic variability of the Andean cat is partitioned among regions, exacerbating the extremely low genetic diversity at the population level.

\section{Evolutionary history}

The origin of the current Andean cat populations seems to be relatively recent, with the common ancestor of their haplotypes dated at approximately 217000 to $290000 \mathrm{yr}$ ago. This period covers an interglacial stage known as the marine oxygen isotope stage 7 (MIS-7, 0.19 to 0.24 MYA) and the glacial MIS-8 (0.24 to 0.3 MYA, Imbrie et al. 1984).

The Andean cat and the pampas cat are considered to be sister species with a common ancestor at 1.8 MYA (Johnson et al. 2006). Between this divergence and 0.3 MYA, the pampas cat lineage diversified into multiple mitochondrial clades (Johnson et al. 1999, Cossíos et al. 2009), whereas our data show no trace of a similar diversification during the same period in the Andean cat lineage. The current lack of mtDNA variation in the Andean cat at the species level could be the result of numerous lineage extinctions due to demographic events that took place during MIS-7 or MIS-8. During interglacial periods, the habitat available for organisms specialised for high altitudes is expected to decrease (e.g. Ethiopian wolf,
Gottelli et al. 2004), suggesting that MIS-7 is the most likely period for the loss of these lineages.

\section{Population structure}

Our analyses of nuclear DNA data indicate the existence of at least 3 significantly differentiated groups of Andean cat populations, distributed as follows, from north to south: group I (localities 2 to 6) occupies central Peru and north-western Bolivia, between $10^{\circ}$ and $18^{\circ} \mathrm{S}$; group II (localities 7 to 10 ) is found between $20^{\circ}$ and $26^{\circ} \mathrm{S}$, in southern Bolivia and northern Argentina, and group III (locality 11) is in central Argentina (Fig. 3). Based on the NADH-5, ATP-8 and $16 \mathrm{~S}$ sequences, the population studied by Napolitano et al. (2008) in northern Chile seems to belong to group I identified here. Interestingly, these population groups have a strong geographical correspondence with the Andean ecoregions. Groups I and II are separated at 18 to $20^{\circ} \mathrm{S}$, where the barrier between Wet Puna and Dry Puna ecoregions is situated. The Andean cat samples of group III were collected in the Patagonian Steppe ecoregion, at elevations as much as $2800 \mathrm{~m}$ lower than the puna (Novaro et al. 2010). The Wet and Dry Punas have drastically different precipitation regimes, with summer precipitations north of $20^{\circ} \mathrm{S}$ and extreme aridity or winter rains south of this limit. The Patagonian Steppe is characterised by a cold scrub-desert with almost constant wind and a unique flora (WWF 2001). The vicuna Vicugna vicugna, another high-altitude specialist, presents important morphological and life history differences between Wet and Dry Puna subspecies (Marín et al. 2007) and is absent from the Patagonian Steppe. Although no life history data are available for the recently discovered Andean cats of group III (Novaro et al. 2010), and morphological data are scarce for all 3 population groups, these important environmental differences suggest that they could have developed unique adaptations.

Haplotype LjaA has a wide geographic range, from 14 to $26^{\circ} \mathrm{S}$. Such a large distribution, beyond the barrier between the Wet and Dry Punas, was not observed for the pampas cat within the last million years (Cossíos et al. 2009). This difference between small Andean felids can be explained by the preference of the Andean cat for high-altitude habitats, and the probable use of parts of the Andes as corridors. This could also explain the continuity of the Andean cat populations between 20 and $26^{\circ} \mathrm{S}$, as opposed to the existence of a structured population for the pampas cat in this same region (Cossíos et al. 2009). In 
contrast, the geographic isolation of the haplotype LjaE seems to be the result of ancient habitat retraction and absence of corridors between 27 and $35^{\circ} \mathrm{S}$, resulting in populations isolated in inland islands.

Because our samples within regions were small, especially for population group III, further analysis of microsatellites, with larger samples and more markers, could allow recognition of a genetic structure within regions, as well as the description of population trends.

\section{Conservation implications}

With the objective of targeting operational units for conservation under the species level, the concepts of 'evolutionarily significant units' (ESUs; Ryder 1986) and 'management units' (MUs; Moritz 1994) were created. The ESU concept implies a different evolutionary history between units, and numerous authors have proposed that ESUs should present ecological differences (e.g. Crandall et al. 2000). Reciprocal monophyly at the mitochondrial level is usually used for recognition of ESUs (Moritz 1994), although it is not mandatory (Paetkau 1999). MUs, on the other hand, are defined as population units with statistically significant differences of allelic frequencies at the nuclear or mitochondrial level (Moritz 1994).

Several factors support the recognition of the Andean cat populations of central Argentina (group III) and the northern populations as 2 different ESUs: (1) geographic separation of haplotype LjaE from the other haplotypes, as well as the topology of the haplotype network and the nuclear data, show that these populations have had a different evolutionary history and that they could be reciprocally monophyletic; (2) unlike the other groups, group III is found in lowaltitude habitats, and may have developed adaptations to those distinct environments; (3) our results suggested that these groups diverged more than 200000 yr ago, which would be sufficient for ESU recognition, even in the absence of ecological data (Paetkau 1999). Within the northern ESU, 2 genetically distinct groups (groups I and II) were recognised. Although these groups share the mitochondrial haplotype LjaA, they present an important divergence for both mitochondrial and nuclear genomes, and for this reason should be considered separate MUs.

In conclusion, the habitat preferences of the Andean cat lead to a strong but particular population structure. Although it would be desirable to confirm our results with a larger sample, the critical conservation status of the Andean cat requires that this structure be taken into account when planning conservation actions, including the choice of areas for monitoring, conservation programmes and the creation of protected areas, as well as for possible captive breeding and reintroduction programmes in the future.

Acknowledgements. Samples were generously provided by L. Villalba, G. Gallardo, R. Palacios, P. Perovic, U. Fajardo, A. Madrid, D. Farfán and J.L. Condori (all members of the Andean Cat Alliance). We also thank M. McClure, M. Chouteau, M. Alday, M. Pelletier, P. Girard, J. Reppucci, D. Alvarez, P. Escobar-Armel, A. Rodriguez and N. Romero for their help during this project, and the Secretaría de Medio Ambiente, Jujuy, Argentina, and the Peruvian National Institute of Natural Resources-INRENA for research permits (No. 13-2007) and institutional support. This work was supported by grants from the Wildlife Conservation Network and the Panthera/Wildlife Conservation Society-Kaplan Graduate Awards Program.

\section{LITERATURE CITED}

Acosta G, Cossíos ED, Lucherini M, Villalba L (2008) Leopardus jacobita. In: IUCN Red List of Threatened Species, Version 2009.1. IUCN. Available at www.iucnredlist.org (accessed on 11 January 2011)

Belkhir KP, Borsa P, Goudet P, Chikhi L, Bonhomme F (1996) GENETIX, logiciel sous Windows ${ }^{\mathrm{TM}}$ pour la génétique des populations. Laboratoire du Génome et Populations, CNRS UPR 9060, Université de Montpellier II, Montpellier. Available at www.genetix.univ-montp2.fr/genetix/ intro.htm

Brodie JF (2009) Is research effort allocated efficiently for conservation? Felidae as a global case study. Biodivers Conserv 18:2927-2939

> Broquet T, Petit E (2004) Quantifying genotyping errors in noninvasive population genetics. Mol Ecol 13:3601-3608

> Cassens I, Van Waerebeek K, Best PB, Crespo EA, Reves J, Milinkovitch MC (2003) The phylogeography of dusky dolphins (Lagenorhynchus obscurus): a critical examination of network methods and rooting procedures. Mol Ecol 12:1781-1792

Clement M, Posada D, Crandall KA (2000) TCS: a computer program to estimate gene genealogies. Mol Ecol 9: 1657-1659

Cossíos ED, Angers B (2006) Identification of Andean felid feces using PCR-RFLP. J Neotrop Mammal 13:239-244

Cossíos ED, Beltrán-Saavedra F, Bennett M, Bernal N (2007a) Manual de metodologías para relevamientos de carnívoros altoandinos. Alianza Gato Andino, Buenos Aires

> Cossíos ED, Madrid A, Condori JL, Fajardo U (2007b) An update on the distribution of Andean cat Oreailurus jacobita and pampas cat Lynchailurus colocolo in Peru. Endang Species Res 3:313-320

Cossíos ED, Ruiz-García M, Lucherini M, Angers A (2009) Influence of ancient glacial periods on the Andean fauna: the case of the pampas cat (Leopardus colocolo). BMC Evol Biol 9:68

> Crandall KA, Bininda-Emonds ORP, Mace GM, Wayne RK (2000) Considering evolutionary processes in conservation biology. Trends Ecol Evol 15:290-295 
Evanno G, Regnaut S, Goudet J (2005) Detecting the number of clusters of individuals using the software STRUCTURE: a simulation study. Mol Ecol 14:2611-2620

Excoffier L, Lischer HEL (2010) Arlequin suite ver 3.5: a new series of programs to perform population genetics analyses under Linux and Windows. Mol Ecol Resour 10: 564-567

> Excoffier L, Smouse PE, Quattro JM (1992) Analysis of molecular variance inferred from metric distances among DNA haplotypes - application to human mitochondrialDNA restriction data. Genetics 131:479-491

Frantz AC, Pope LC, Carpenter PJ (2003) Reliable microsatellite genotyping of the Eurasian badger (Meles meles) using faecal DNA. Mol Ecol 12:1649-1661

Freeman AR, MacHugh DE, McKeown S, Walzer C, McConnell DJ, Bradley DG (2001) Sequence variation in the mitochondrial DNA control region of wild African cheetahs (Acinonyx jubatus). Heredity 86:355-362

Glaubitz JC (2004) CONVERT (version 1.2): a user-friendly program to reformat diploid genotypic data for commonly used population genetic software packages. Mol Ecol Notes 4:309-310

> Gottelli D, Marino J, Sillero-Zubiri C, Funk SM (2004) The effect of the last glacial age on speciation and population structure of the endangered Ethiopian wolf (Canis simensis). Mol Ecol 13:2275-2286

Goudet J (1995) FSTAT (vers. 1.2): a computer program to calculate F-statistics. J Hered 86:485-486

- Grisolia AB, Moreno VR, Campagnari F, Milazzotto MP, Garcia JF, Adania CH, Souza EB (2007) Genetic diversity of microsatellite loci in Leopardus pardalis, Leopardus wiedii and Leopardus tigrinus. Genet Mol Res 6:382-389

> Guo SW, Thompson EA (1992) Performing the exact test of Hardy-Weinberg proportion for multiple alleles. Biometrics 48:361-372

Imbrie LJ, Hays JD, Martinson DG, McIntyre A and others (1984) The orbital theory of Pleistocene climate: support from a revised chronology of the marine $\delta^{18} \mathrm{O}$ record. In: Berger A, Imbrie J, Hays JD, Kukla G, Saltzman B (eds) Milankovitch and climate. D Reidel, Dordrecht and London, p 269-305

> Johnson WE, Culver M, Iriarte JA, Eizirik E, Seymour KL, O'Brien SJ (1998) Tracking the evolution of the elusive Andean mountain cat (Oreailurus jacobita) from mitochondrial DNA. J Hered 89:227-232

> Johnson WE, Slattery JP, Eizirik E, Kim JH and others (1999) Disparate phylogeographic patterns of molecular genetic variation in four closely related South American small cat species. Mol Ecol 8:S79-S94

> Johnson WE, Godoy JA, Palomares F, Delibes M, Fernandes M, Revilla E, O'Brien SJ (2004) Phylogenetic and phylogeographic analysis of Iberian lynx populations. J Hered 95:19-28

Johnson WE, Eizirik E, Pecon-Slattery J, Murphy WJ, Antunes A, Teeling E, O'Brien SJ (2006) The Late Miocene radiation of modern Felidae: a genetic assessment. Science 311:73-77

Kohn MH, Wayne RK (1997) Facts from feces revisited. Trends Ecol Evol 12:223-227

> Lopez JV, Cevario S, O'Brien SJ (1996) Complete nucleotide sequences of the domestic cat (Felis catus) mitochondrial genome and a transposed mtDNA tandem repeat (Numt) in the nuclear genome. Genomics 33:229-246

Lucherini M, Luengos E (2003) Intraguild competition as a potential factor affecting the conservation of two endan- gered cats in Argentina. Endang Spec Update 20: 211-220

- Lucherini M, Merino MJ (2008) Perceptions of human-carnivore conflicts in the High Andes of Argentina. Mt Res Dev 28:81-85

Lucherini M, Vidal EL, Merino MJ (2008) How rare is the rare Andean cat? Mammalia 72:95-101

Marín JC, Casey CS, Kadwell M, Yaya K and others (2007) Mitochondrial phylogeography and demographic history of the vicuna: implications for conservation. Heredity 99: 70-80

> Marino J, Bennett M, Cossios D, Iriarte A and others (2011) Conservation implications of bioclimatic constraints to Andean cat distribution: a modeling application for rare species. Divers Distrib 17:311-322

Menotti-Raymond M, David VA, Lyons LA, Schäffer AA, Tomlin JF, Hutton MK, O'Brien SJ (1999) A genetic linkage map of microsatellites in the domestic cat (Felis catus). Genomics 57:9-23

> Moritz C (1994) Defining 'Evolutionarily Significant Units' for conservation. Trends Ecol Evol 9:373-375

- Napolitano C, Bennett M, Johnson WE, O'Brien SJ and others (2008) Ecological and biogeographical inferences on two sympatric and enigmatic Andean cat species using genetic identification of faecal samples. Mol Ecol 17: 678-690

Nei M (1987) Molecular evolutionary genetics. Columbia University Press, New York, NY

Novaro A, Walker S, Palacios R, DiMartino S and others (2010) Endangered Andean cat distribution beyond the Andes in Patagonia. Cat News 53:8-10

Nowell K, Jackson P, IUCN/SSC Cat Specialist Group (1996) Wild cats: status survey and conservation action plan. International Union for Conservation of Nature, Gland

Olson DM, Dinerstein E, Wikramanayake ED, Burgess ND and others (2001) Terrestrial ecoregions of the world: a new map of life on Earth. A new global map of terrestrial ecoregions provides an innovative tool for conserving biodiversity. Bioscience 51:933-938

> Paetkau D (1999) Using genetics to identify intraspecific conservation units: a critique of current methods. Conserv Biol 13:1507-1509

> Perovic P, Walker S, Novaro A (2003) New records of the Endangered Andean mountain cat in northern Argentina. Oryx 37:374-377

Posada D, Crandall KA (1998) MODELTEST: testing the model of DNA substitution. Bioinformatics 14:817-818

> Pritchard JK, Stephens M, Donnelly P (2000) Inference of population structure using multilocus genotype data. Genetics 155:945-959

Raymond M, Rousset F (1995) Genepop (version 1.2). Population genetics software for exact tests and ecumenicism. J Hered 86:248-249

Ruiz-García M (2007) Genética de poblaciones: teoría y aplicación a la conservación de mamíferos neotropicales (oso andino y delfín rosado). Bol R Soc Esp Hist Nat Sect Biol 102:99-126

Ryder OA (1986) Species conservation and systematics - the dilemma of subspecies. Trends Ecol Evol 1:9-10

Sambrook J, Fritsch EF, Maniatis T (1989) Molecular cloning: a laboratory manual, 2nd edn. Cold Spring Harbor Laboratory Press, Cold Spring Harbor, NY

Schneider S, Roessli D, Excoffier L (2000) Arlequin: a software for population genetics data analysis. University of Geneva, Geneva 
Scrocchi GJ, Halloy SP (1986) Notas sistemáticas, ecológicas, etológicas y biogeográficas sobre el gato andino. Acta Zool Lilloana 23:157-180

Sorli LE, Martínez FD, Lardelli U, Brandi S (2006) Andean cat in Mendoza, Argentina - furthest south and lowest elevation ever recorded. Cat News 44:24

Swofford DL (1993) PAUP* : phylogenetic analysis using parsimony ( ${ }^{*}$ and other methods). Version 4.0. Sinauer Associates, Sunderland, MA

Taberlet P, Griffin S, Goossens B, Questiau S and others (1996) Reliable genotyping of samples with very low DNA quantities using PCR. Nucleic Acids Res 24: 3189-3194

Taberlet P, Waits LP, Luikart G (1999) Noninvasive genetic sampling: look before you leap. Trends Ecol Evol 14: 323-327

Tajima F (1983) Evolutionary relationship of DNA sequences in finite populations. Genetics 105:437-460

Tamura K, Nei M (1993) Estimation of the number of nucleotide substitutions in the control region of mitochondrial DNA in humans and chimpanzees. Mol Biol Evol 10:512-526

Tang H, Siegmund DO, Shen P, Oefner PJ, Feldman MW (2002) Frequentist estimation of coalescence times from nucleotide sequence data using a tree-based partition.

Editorial responsibility: Brendan Godley, University of Exeter, Cornwall Campus, UK
Genetics 161:447-459

Templeton AR, Crandall KA, Sing CF (1992) A cladistic analysis of phenotypic associations with haplotypes inferred from restriction endonuclease mapping and DNA sequence data. Genetics 132:619-633

Thompson JD, Higgins DG, Gibson TJ (1994) CLUSTAL W: improving the sensitivity of progressive multiple sequence alignment through sequence weighting, position-specific gap penalties and weight matrix choice. Nucleic Acids Res 22:4673-4680

Villalba L, Lucherini M, Walker S, Cossíos D and others (2004) The Andean cat: a conservation action plan. Andean Cat Alliance, La Paz

Walker RS, Novaro AJ, Perovic P, Palacios R and others (2007) Diets of three species of Andean carnivores in high-altitude deserts of Argentina. J Mammal 88:519-525

Wasser SK, Houston CS, Koehler GM, Cadd GG, Fain SR (1997) Techniques for application of faecal DNA methods to field studies of ursids. Mol Ecol 6:1091-1097

WWF (World Wildlife Fund) (2001) Terrestrial biorealms. Neotropical. Available at www.worldwildlife.org/wild world/profiles (accessed 11 January 2011)

WWF (2006) WildFinder: online database of species distributions. Version 01.06. Available at www.worldwildlife. org/wildfinder (accessed 11 January 2011)

Submitted: February 28, 2011; Accepted: November 25, 2011 Proofs received from author(s): February 10, 2012 